\title{
Effects of $\alpha$-Thalassemia and Sickle Polymerization Tendency on the Urine-concentrating Defect of Individuals with Sickle Cell Trait
}

\author{
Akshey K. Gupta, Kent A. Kirchner, Rosie Nicholson, Junius G. Adams III, Alan N. Schechter,* \\ Constance T. Noguchi, * and Martin H. Steinberg \\ Department of Medicine and Veterans Affairs Medical Center, University of Mississippi School of Medicine, Jackson, Mississippi 39216; \\ and the *Laboratory of Chemical Biology, National Institute of Diabetes and Digestive and Kidney Diseases, \\ National Institutes of Health, Bethesda, Maryland 20892
}

\begin{abstract}
A defect in urine concentrating ability occurs in individuals with sickle cell trait (HbAS). This may result from intracellular polymerization of sickle hemoglobin (HbS) in erythrocytes, leading to microvascular occlusion, in the vasa recta of the renal medulla. To test the hypothesis that the severity of the concentrating defect is related to the percentage of sickle hemoglobin present in erythrocytes, urinary concentrating ability was examined after overnight water deprivation, and intranasal desmopressin acetate (dDAVP) in 27 individuals with HbAS. The HbAS individuals were separated into those who had a normal $\alpha$-globin genotype $(\alpha \alpha / \alpha \alpha)$, and those who were either heterozygous $(-\alpha / \alpha \alpha)$ or homozygous $(-\alpha /-\alpha)$ for gene-deletion $\alpha$-thalassemia, because $\alpha$-thalassemia modulates the $\mathrm{HbS}$ concentration in HbAS. The urinary concentrating ability was less in the $\alpha \alpha / \alpha \alpha$ genotype than in the $-\alpha / \alpha \alpha$ or $-\alpha /-\alpha$ genotypes $(P$ $<0.05)$. After dDAVP, the urine osmolality was greater in patients with the $-\alpha /-\alpha$ genotype than with the $-\alpha / \alpha \alpha$ genotype $\left(882 \pm 37\right.$ vs. $\left.672 \pm 38 \mathrm{mOsm} / \mathrm{kg} \mathrm{H}_{2} \mathrm{O}\right)(P<0.05)$; patients with the $-\alpha / \alpha \alpha$ genotype had greater concentrating ability than individuals with a normal $\alpha$-globin gene arrangement. There was an inverse linear correlation between urinary osmolality after dDAVP and the percentage $\mathrm{HbS}$ in all patients studied ( $r$ $=-0.654 ; P<0.05)$. A linear correlation also existed for urine concentrating ability and the calculated polymerization tendencies for an oxygen saturation of 0.4 and $O(r=-0.62$ and 0.69 , respectively). We conclude that the severity of hyposthenuria in HbAS is heterogeneous. It is determined by the amount of HbS polymer, that in turn is dependent upon the percentage $\mathrm{HbS}$, which is itself related to the $\alpha$-globin genotype. (J. Clin. Invest. 1991. 88:1963-1968.) Key words: sickle hemoglobin • renal function $\bullet$ hyposthenuria
\end{abstract}

\section{Introduction}

Impaired ability to produce a concentrated urine is usually present in individuals with the sickle cell trait $(\operatorname{HbAS})^{1}(1,2)$.

Address all correspondence to Kent Kirchner, M.D., Department of Medicine, Division of Nephrology, University of Mississippi Medical Center, 2500 N. State St., Jackson, MS 39216. 1991.

Received for publication 25 March 1991 and in revised form $22 \mathrm{July}$

1. Abbreviations used in this paper: dDAVP, desmopressin acetate; HbAS, sickle cell trait; HbS, sickle hemoglobin; MCHC, mean corpuscular hemoglobin concentration.

J. Clin. Invest.

(c) The American Society for Clinical Investigation, Inc. $0021-9738 / 91 / 12 / 1963 / 06 \quad \$ 2.00$

Volume 88, December 1991, 1963-1968
This defect has been attributed to altered blood flow through the vasa recta of the renal medulla $(3,4)$. The concentration of sickle hemoglobin (HbS) polymer is a major determinant of the abnormal rheologic behavior of HbS-containing cells (5-11). Even in HbAS, where the erythrocytes are morphologically normal, $\mathrm{HbS}$ polymer may be present under physiological conditions at reduced oxygen saturations. These conditions are met in the renal medulla, where hypertonicity and acidosis also favor the polymerization tendency of $\mathrm{HbS}$ (12).

There is a trimodal distribution of $\mathrm{HbS}$ levels in carriers of HbAS (13-15). This is caused by the interaction of HbAS with $\alpha$-thalassemia $(14,16-18)$. Gene-deletion $\alpha$-thalassemia is common in blacks. The deletion of $3.7 \mathrm{~kb}$ of DNA, containing one of the two linked $\alpha$-globin genes $(-\alpha / \alpha \alpha)$, is found in $\sim 30 \%$ of this population (18-20). $2 \%$ are homozygous for this deletion $(-\alpha /-\alpha)$. Non-gene deletion $\alpha$-thalassemia is rare (21). In HbAS with a normal $\alpha$-globin genotype $(\alpha \alpha / \alpha \alpha)$, erythrocytes contain $\sim 40 \% \mathrm{HbS}$. The deficit of $\alpha$-globin chains caused by $\alpha$-thalassemia, modifies the assembly of the hemoglobin tetramer $(22,23)$. The negatively charged $\beta^{A}$-chain of normal hemoglobin forms $\alpha \beta$ dimers with the positively charged $\alpha$-globin chain more readily than the less negatively charged $\beta^{s}$-chain of $\mathrm{HbS}(18)$. Therefore, in $\mathrm{HbAS}, \mathrm{HbA}$ tetramers are formed in the erythrocyte in preference to $\mathrm{HbS}$ tetramers. With a deficit in $\alpha$-globin chains, the concentration of $\mathrm{HbS}$ falls further. In HbAS individuals with the $(-\alpha / \alpha \alpha)$ genotype, there is $\sim 35 \% \mathrm{HbS}$, whereas the $\mathrm{HbS}$ level in the $(-\alpha /-\alpha)$ genotype is $\sim 30 \%$ (18). The very rare patient with loss of three $\alpha$-globin genes $(--/-\alpha)$ has $20-25 \% \mathrm{HbS}(18,24)$.

The primary determinants of intracellular polymer formation are oxygen saturation, hemoglobin composition, and hemoglobin concentration (5). For example, at oxygen saturations $<0.4$, polymerization in HbAS cells becomes important and increases as oxygen saturation decreases (8). When fully deoxygenated, HbAS erythrocytes at normal mean corpuscular hemoglobin concentrations (MCHC), can contain $30-40 \%$ intracellular polymer (as measured by NMR techniques) consisting primarily of $\mathrm{HbS}$ but containing some $\mathrm{HbA}(25)$. The increase in MCHC that is likely to occur in the renal medulla further accentuates the polymerization tendency both due to the increased $\mathrm{HbS}$ concentration itself and due to the excessive crowding, or very nonideal behavior of hemoglobin molecules at these extraordinarily high intracellular protein concentrations. The acidic milieu of the medulla may decrease intracellular $\mathrm{pH}$, which in turn increases polymerization tendency by lowering the solubility of deoxy $\operatorname{HbS}(6,12)$ and perhaps increasing cell density (26). The net result of these effects provides conditions that promote significant intracellular polymer formation in the HbAS erythrocyte at the reduced oxygen saturation of this tissue.

We hypothesized that the renal concentrating defect of individuals with HbAS may vary in severity depending upon the 
$\alpha$-globin genotype, percentage $\mathrm{HbS}$, and the calculated polymer tendency of the erythrocytes at physiologic oxygen saturations. The current study was designed to test this hypothesis.

\section{Methods}

Patients. Patients with HbAS were identified from the records of the VA Sickle Cell Screening and Education Program at the Jackson VA Medical Center. On the basis of hemoglobin electrophoresis, they were initially separated into groups with $\mathrm{HbS}$ levels $>35 \%, 30-35 \%$, and $<30 \%$. To be eligible for the study patients had to be at least $21 \mathrm{yr}$ of age, and have no history of cardiac, liver, or renal disease. Individuals with diabetes mellitus or psychiatric illness were excluded. The patients selected for the study had complete blood counts, including erythrocyte indices, determined on an electronic cell counter, remeasurement of their HbS levels by HPLC, and determination of their serum creatinine. In individuals who were not anemic $(\mathrm{PCV}>35)$ and had normal renal function (serum creatinine, $\leq 1.5 \mathrm{mg} / \mathrm{dl}$ ), the $\alpha$-globin genotype was determined and their ability to concentrate maximally their urine was ascertained. This study was approved by the Institutional Review Board.

$\alpha$-Globin gene mapping. DNA was isolated from blood leukocytes (27) and digested to completion with the restriction endonucleases Bam $\mathrm{H} 1$ and Bgl II. The restricted DNA was fractionated by electrophoresis on $0.8 \%$ agarose gels and then transferred to a Nytran membrane by the method of Southern (28). The membrane was hybridized to a 1.4-kb PST 1 fragment containing the $\alpha 2$ globin gene, that was labeled with digoxigenin-dUDP. The blot was developed with an anti-digoxigenin-alkaline phosphatase conjugant (Boehringer Mannheim Biochemicals, Indianapolis, IN).

Hemoglobin fractionation and quantification. The level of hemoglobin $A$ and $S$ in the hemolysate was determined by HPLC on CX-100 columns (29).

Hemoglobin $S$ polymer calculations. In earlier work, polymerization was measured by NMR techniques as a function of oxygen saturation for $\mathrm{HbSS}$ and $\mathrm{HbAS}$ cells, as well as HbSS cells fractionated by density (30-32). It was found that these experimental results could be reproduced by an algorithm developed for this purpose, based on our understanding of the physical chemistry of polymerization. Thus, values of $\mathrm{MCHC}$ and the percentages of $\mathrm{HbS}$ and $\mathrm{HbA}$ can be used to predict polymer fraction for any given oxygen saturation (9). The calculations are based on a two-phase model in which free hemoglobin molecules are considered to be in equilibrium with the polymer phase at a concentration of $69 \mathrm{~g} / \mathrm{dl}$. Mixtures of $\mathrm{HbS}$ and $\mathrm{HbA}$ can form heterodimeric hemoglobin tetramers $\left(\alpha_{2} \beta^{\mathrm{A}} \beta^{\mathrm{S}}\right)$. Based on polymerization studies of mixtures of $\mathrm{HbS}$ and $\mathrm{HbA}$ solutions (25), the polymerization tendency of the heterodimer hemoglobin $\left(\alpha_{2} \beta^{A} \beta^{S}\right)$ is assumed to be 0.4 times that of a $\mathrm{HbS}\left(\alpha_{2} \beta_{2}^{\mathrm{S}}\right)$ molecule. The homodimeric $\mathrm{HbA}$ $\left(\alpha_{2} \beta_{2}^{\mathrm{A}}\right)$ molecule does not enter into the polymer phase to a significant extent. A binomial distribution is used to determine the distribution of the $\mathrm{HbA}, \mathrm{HbS}$, and heterodimer-containing molecules. Due to the expected high MCHC in the renal medulla, the calculations take into account nonideal behaviors of both the hemoglobin and the solvent molecules. To calculate the fraction of polymer at nonzero oxygen saturation values, the percentage of $\mathrm{HbS}, \mathrm{HbA}$, and $\mathrm{HbF}$ were used to determine the solubility, $C_{8}$, of a hemoglobin mixture of comparable composition at $40 \%$ oxygen saturation and higher. $C_{\mathrm{s}}$ is given by the equation, $\left(\gamma_{\mathrm{s}} C_{\mathrm{s}} / \gamma_{\mathrm{o}} C_{\mathrm{o}}\right)\left(a_{\mathrm{s}} / a_{\mathrm{o}}\right)^{\mathrm{r}}=1 /\left(\sum_{\mathrm{i}}\left[x_{\mathrm{i}} e_{\mathrm{i}}\right]\right)$, where $C_{\mathrm{o}}$ is the solubility of pure deoxyhemoglobin $S, \gamma_{s}$ and $\gamma_{0}$ are the activity coefficients corresponding to $C_{\mathrm{s}}$ and $C_{\mathrm{o}}, a_{\mathrm{s}}$ and $a_{\mathrm{o}}$ are the activities of water in the solvent and deoxyhemoglobin $\mathrm{S}$ at $C_{\mathrm{o}}, r$ is the ratio of moles of solvent water to moles of hemoglobin in the polymer phase, $x_{\mathrm{i}}$ is the mole fraction of each hemoglobin species, $e_{\mathrm{i}}$ is the relative probability that the hemoglobin species can be incorporated into the polymer phase relative to deoxyhemoglobin $S\left(e_{\mathrm{i}}\right.$ for deoxyhemoglobin $S$ equals 1$)$ and $\Sigma_{\mathrm{i}}$ represents the summation over all hemoglobin species. The polymer fraction was determined by using the conservation of mass relationship in which the polymer fraction plus the soluble fraction equals 1 . The polymer fraction is equal to $C_{\mathrm{p}}\left(\mathrm{MCHC}-C_{\mathrm{z}}\right) /\left[\mathrm{MCHC}\left(C_{\mathrm{p}}-C_{\mathrm{s}}\right)\right]$, where $C_{\mathrm{p}}$ is the concentration of the polymer phase $(69 \mathrm{~g} / \mathrm{dl})(9)$.

Urinary concentrating ability. Before determining the maximal urine concentrating ability, diuretics, nonsteroidal antiinflammatory drugs, and aspirin were discontinued for at least 1 wk. No participant was taking phenothiazines. The subjects arrived at the hospital after an overnight fast, having been instructed to discard their first morning voided urine. After the collection of the next spontaneously voided urine, each received $10 \mu \mathrm{g}$ of desmopressin acetate (dDAVP; Rorer Pharmaceuticals, Fort Washington, PA) by intranasal administration. The next 30-min voided urine sample was discarded and urine voided between 30 and $60 \mathrm{~min}$ after dDAVP administration was collected. To exclude the possibility that $\alpha$-globin genotype influences the time necessary to achieve maximal urinary osmolality after dDAVP, urine osmolality was measured at 60 -min intervals using a double voiding technique in a subset of each of three groups at a separate clinic visit. Urine osmolality was measured by freezing point depression using a microosmometer (model 3MO; Advanced Instruments, Needham Heights, MO). Urine analysis was performed on overnight voided samples in each of the genotype groups.

Statistical analysis. Analysis of variance was used to determine statistically significant differences within the groups. If analysis of variance indicated that a significant difference was present, the Bonferroni's modification of the $t$ test was used to determine statistically significant differences between the groups. Linear regression was used to examine the relationship between percentage $\mathrm{HbS}$ and sickle polymer and urinary osmolality (33). $P<0.05$ was considered significant.

\section{Results}

Patients. We studied 27 black patients, one female and 26 males. The means of the ages, serum creatinine, urea nitrogen, potassium, calcium, and total protein concentrations, hemoglobin concentrations, and $\mathrm{HbS}$ levels in the three $\alpha$-globin genotype groups are shown in Table I. One additional patient had five $\alpha$-globin genes $(\alpha \alpha \alpha / \alpha \alpha)$ and is included in the $(\alpha \alpha / \alpha \alpha)$

Table I. Laboratory Characteristics of Sickle Cell Trait Individuals Studied

\begin{tabular}{|c|c|c|c|c|c|c|c|c|}
\hline$\alpha$-Globin genes & Age & Hemoglobin & HbS & BUN & Creatinine & $\begin{array}{c}\text { Serum } \\
\text { potassium }\end{array}$ & $\begin{array}{l}\text { Serum } \\
\text { calcium }\end{array}$ & $\begin{array}{l}\text { Total } \\
\text { serum } \\
\text { protein }\end{array}$ \\
\hline & $y$ & $g / d l$ & $\%$ & $m g / d l$ & $m g / d l$ & meq/liter & $m g / d l$ & $g / d l$ \\
\hline$\alpha \alpha / \alpha \alpha(n=15)$ & $53 \pm 4$ & $14.3 \pm 0.3$ & $41.8 \pm 0.5$ & $11.53 \pm 0.77$ & $1.05 \pm 0.05$ & $4.19 \pm 0.09^{*}$ & $9.01 \pm 0.09^{\ddagger}$ & $7.26 \pm 0.13^{*}$ \\
\hline$-\alpha / \alpha \alpha(n=9)$ & $48 \pm 4$ & $13.7 \pm 0.5$ & $36.8 \pm 0.8^{\S}$ & $12.33 \pm 1.81$ & $1.02 \pm 0.06$ & $4.03 \pm 0.16$ & $9.03 \pm 0.09$ & $7.37 \pm 0.22$ \\
\hline$-\alpha /-\alpha(n=3)$ & $53 \pm 6$ & $14.4 \pm 0.3$ & $29.2 \pm 0.3^{\prime \prime}$ & $14.67 \pm 2.60$ & $1.13 \pm 0.09$ & $4.30 \pm 0.17$ & $9.13 \pm 0.14$ & $7.37 \pm 0.24$ \\
\hline
\end{tabular}

The values presented are the means \pm SE. ${ }^{*} n=14$, these determinations only; ${ }^{*} n=13$, this determination only. ${ }^{8} P<0.001$ vs. $\alpha \alpha / \alpha \alpha ;{ }^{11} P<.001$ vs. $-\alpha / \alpha \alpha$. 

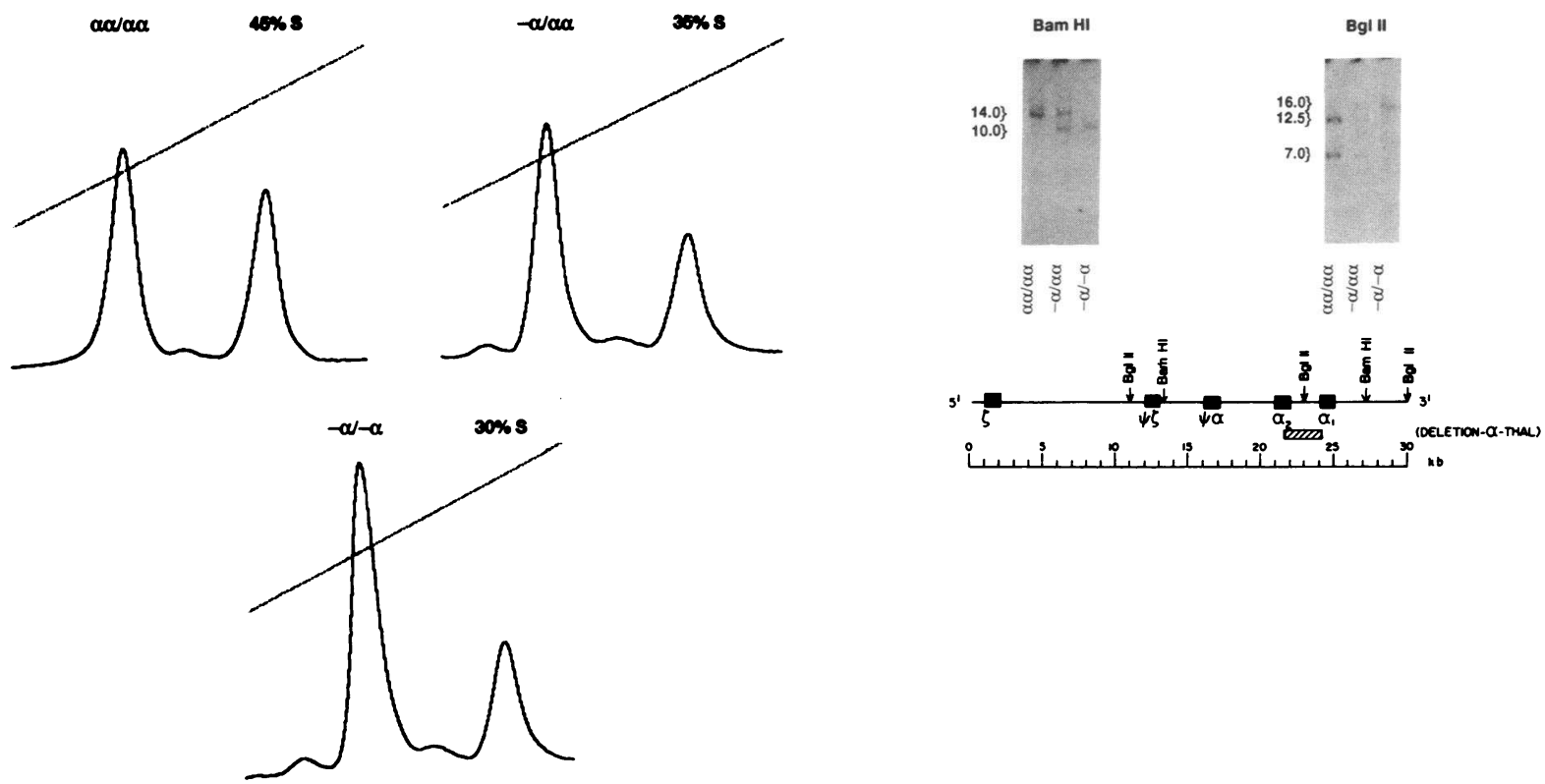

Figure 1. $\alpha$-Globin genotypes and quantification of hemoglobins $\mathrm{A}$ and $\mathrm{S}$ in individuals with sickle cell trait and four, three, and two $\alpha$-globin genes. (Left) Examples of the separation and quantification of hemoglobins $A$ and $S$ in individuals with four, three, and two $\alpha$-globin genes. (Right) Examples of restriction endonuclease mapping of the $\alpha$-globin genes in the same individuals. With the normal complement of four $\alpha$ globin genes, the $\mathrm{HbS}$ level is $\sim 40 \%$. When hybridized with an $\alpha$-globin gene-specific probe, this genotype $(\alpha \alpha / \alpha \alpha)$ produces $14.0 \mathrm{~kb}$ Bam $\mathrm{H} 1$, and 12.5 and 7.0 Bgl II fragments. Patients heterozygous for $-\alpha^{3.7}(-\alpha / \alpha \alpha)$ have $\mathrm{HbS}$ levels of $\sim 35 \%$. Loss of a single $\alpha$-globin gene leads to 14.0 and 10.0 Bam $\mathrm{Hl}$, and 16.0, 12.5, and 7.0 Bgl II fragments. Homozygotes for this deletion $(-\alpha /-\alpha)$ have HbS levels of $\sim 30 \%$. Deletion of a single gene from each chromosome results in a $10.0 \mathrm{~kb}$ Bam $\mathrm{H} 1$ and $16.0 \mathrm{~kb}$ Bgl II fragment.

group. The $\mathrm{HbS}$ levels differed significantly among these groups. There were no other statistically significant differences. The determination of $\alpha$-globin genotype and the quantification of $\mathrm{HbS}$ in a representative patient from each of the genotypes examined is shown in Fig. 1.

Urine concentrating ability. The urine concentrating ability after either overnight water deprivation or intranasal dDAVP is shown in Fig. 2. The ability to concentrate urine was attenuated with increasing number of $\alpha$-globin genes both after overnight water deprivation or after intranasal dDAVP. Intranasal dDAVP increased urine osmolality above that measured after overnight water deprivation in each of the three groups. The percent increase in urinary osmolality after dDAVP was $5.4 \pm 1.4 \%$ in the $\alpha \alpha / \alpha \alpha$ genotype; $6.8 \pm 1.2 \%$ in the $-\alpha / \alpha \alpha$ genotype and $12.7 \pm 4.6 \%$ in the $-\alpha /-\alpha$ genotype. These values were not different. Urinary osmolality was not different

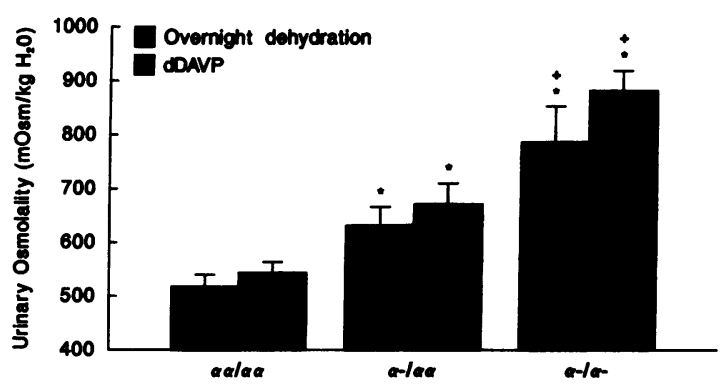

Figure 2. Maximal urinary concentrating ability after overnight fluid deprivation or intranasal dDAVP in individuals with sickle cell trait and either four, three, or two $\alpha$-globin genes. ${ }^{*} P<0.05$ for comparison of results in individuals with four vs. three $\alpha$-genes; ${ }^{+} P<0.05$ for comparison of results in individuals with three vs. two $\alpha$-genes.
1,2 , or $3 \mathrm{~h}$ after dDAVP for any of the $\alpha$-genotype groups in the subset of subjects so studied (Table II). Although trace protein was frequently observed in overnight voided urines within each genotype group, there were no consistent abnormalities which distinguished one group from the other (data not shown).

There was an inverse linear correlation between $\mathrm{HbS}$ percentage and urinary concentrating ability after dDAVP with $r$ $=-0.654$ (Fig. 3). This correlation approach $-1(r=-0.99)$ when the mean values for urine concentrating ability and percentage $\mathrm{HbS}$ in the three $\alpha$-globin genotype groups were employed (Fig. 3).

Polymer formation and urine concentration. The potential for polymer formation is maximal at complete deoxygenation and was measured to be $\sim 0.35$ by NMR techniques in cells from individuals with $\mathrm{HbAS}$ and normal $\alpha$-globin genotypes $(8,9)$. For HbAS erythrocytes, calculated polymer fraction at complete deoxygenation varies, with mean values of $0.34 \pm 0.03,0.29 \pm 0.03$, and $0.20 \pm 0.01$ for the $(\alpha \alpha / \alpha \alpha),(-\alpha /$

Table II. Urinary Osmolality 1,2 , and $3 \mathrm{~h}$ after Intranasal dDAVP in a Subset of the Study Population

\begin{tabular}{lccc}
\hline & \multicolumn{3}{c}{$U_{\text {osm }}$} \\
\cline { 2 - 4 } & $1 \mathrm{~h}$ & $2 \mathrm{~h}$ & $3 \mathrm{~h}$ \\
\hline & & mosmol/kg $\mathrm{H}_{2} \mathrm{O}$ \\
$\alpha \alpha / \alpha \alpha(n=9)$ & $530 \pm 14$ & $533 \pm 15$ & $533 \pm 14$ \\
$-\alpha / \alpha \alpha(n=6)$ & $639 \pm 46$ & $636 \pm 44$ & $640 \pm 45$ \\
$-\alpha /-\alpha(n=3)$ & $885 \pm 72$ & $873 \pm 73$ & $884 \pm 78$ \\
\hline
\end{tabular}

Values are means $\pm \mathrm{SE}$ 


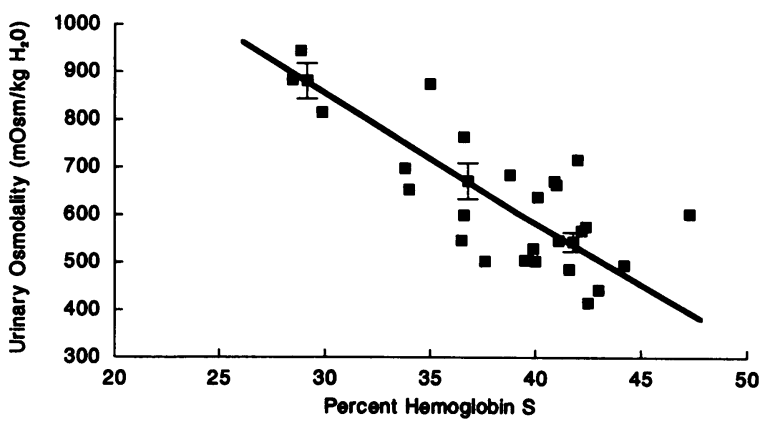

Figure 3. Correlation between urinary osmolality after intranasal dDAVP and percentage sickle hemoglobin in individuals with sickle cell trait. The group mean values are indicated by the error bars. The equation for this line is $y=21.2 X+1410 ; r=0.999$. The squares represent individual data points. The equation for this regression line is $y=17.9 X+1280 ; r=0.654 ; P<0.05$.

$\alpha \alpha$ ), and $(-\alpha /-\alpha) \alpha$-globin genotypes, respectively (Fig. 4). The decrease in polymer fraction with a fall in the number of $\alpha$-globin genes reflects primarily the fall in $\mathrm{HbS}$ concentration, with a small contribution from the variation in MCHC. As oxygen saturation increases, the hemoglobin solubility increases and the extent of polymerization decreases. The polymer fraction for HbAS erythrocytes from individuals with $(-\alpha /$ $-\alpha$ ) is smaller at all oxygen saturations compared with the genotypes $(-\alpha / \alpha \alpha)$ and $(\alpha \alpha / \alpha \alpha)$. For the $(-\alpha /-\alpha)$ genotype, polymer fraction becomes zero between 0.4 and 0.5 oxygen saturation. For the $(-\alpha / \alpha \alpha)$ genotype, zero polymer fraction is reached at oxygen saturations $>0.5$. The $(\alpha \alpha / \alpha \alpha)$ genotype has the highest level of $\mathrm{HbS}$, and polymer fraction does not become zero until the oxygen saturation is 0.6 or higher.

It is likely that the MCHC of erythrocytes that traverse the renal medulla is higher than the MCHC of these cells in other regions of the circulation as a consequence of the high medullary salt concentration. In Fig. 4 (inset), we show the effect of raising the $\mathrm{MCHC}$ of $\mathrm{HbAS}$ cells to 40 , on the calculated $\mathrm{HbS}$ polymer fraction at different oxygen saturations. In contrast to HbAS cells with a normal MCHC, the polymerization tendency now becomes zero at an oxygen saturation between 0.8 and 0.9 and the polymer fraction at 0.4 oxygen saturation is $>0.35$.

The low oxygen saturation of the renal medulla suggests that comparisons of the polymerization tendency at low oxygen saturations may be more meaningful than the examination of polymer fraction at the oxygen saturations customarily

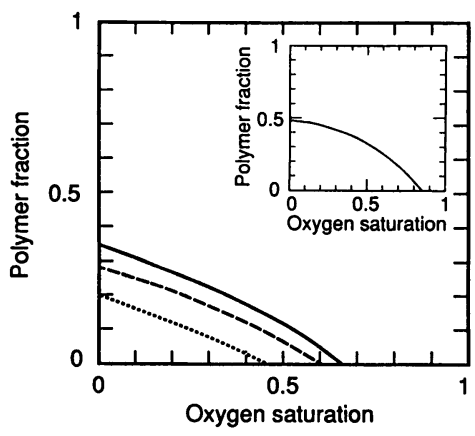

Figure 4. Calculated polymer fraction for sickle trait erythrocytes at varying oxygen saturations. The mean values for MCHC and percentage hemoglobin $\mathrm{S}$ for $(\alpha \alpha / \alpha \alpha)$ (solid line), $(-\alpha /$ $\alpha \alpha)$ (dashed line), and $(-\alpha /$ $-\alpha)($ dotted line $)$ were used to predict the polymer fraction at equilibrium. (Inset) A similar plot for $\mathrm{HbAS}$ erythrocytes with a normal $\alpha$-globin genotype and an $\mathrm{MCHC}$ of 40 . found in the arteriolar circulation. Therefore, the urine concentrating ability after dDAVP was compared to the calculated polymer fraction for a range of oxygen saturations from 0.5 to 0.1 as well as the saturation at which polymer fraction becomes zero. A linear correlation between the urine concentrating ability and polymerization tendencies, represented by the polymer fraction at 0.4 oxygen saturation and the oxygen saturation at which polymer fraction became zero, was observed $(r=-0.62$ and -0.69 , respectively) (Fig. 5). The mean polymer fractions for individuals with the $(-\alpha /-\alpha),(-\alpha / \alpha \alpha)$, and $(\alpha \alpha / \alpha \alpha)$ genotypes at 0.4 oxygen saturation, were $0.03 \pm 0.01,0.12 \pm 0.03$, and $0.17 \pm 0.03$, respectively (Fig. 4).

Estimations have been made that the oxygen saturation at the papillary tip may be as low as $0.1-0.2(34)$. The polymerization tendency at 0.25 oxygen saturation was $0.10,0.19$, and 0.25 , in individuals with 2,3 , and $4 \alpha$-genes, respectively. The correlations between tests of renal function and polymerization tendency were even tighter when the mean values for urine concentrating ability for each $\alpha$-globin genotype group were compared with the mean values for polymer formation. In this analysis, an $r$ value of $>0.99$ was found for 0.4 oxygen saturation and for the oxygen saturation at which polymer fraction became zero (Fig. 5).

\section{Discussion}

The current study demonstrates that the severity of the urine concentrating defect associated with the HbAS genotype is directly related to the erythrocyte $\mathrm{HbS}$ concentration, a function of $\alpha$-globin genotype. Calculation of the expected amounts of $\mathrm{HbS}$ polymer at partial pressures of oxygen of 0.4 and normal MCHC value, shows an inverse linear relationship between the amount of $\mathrm{HbS}$ polymer and urinary concentrating ability. The polymerization tendency is even greater at the very low oxygen saturations that are present at the renal papillary tip and when the MCHC of erythrocytes is increased to approximate a value likely to occur in the renal medulla. These observations are consistent with the hypothesis that the tendency for intracellular sickle hemoglobin polymerization found in the erythrocytes present in the vasa recta of the renal medulla directly determines the urinary concentrating ability in $\mathrm{HbAS}$.

Individuals with HbAS have a normal lifespan and do not suffer the vaso-occlusive episodes that typify sickle cell anemia (HbSS) $(32,35)$. Nevertheless, hematuria and a reduction in

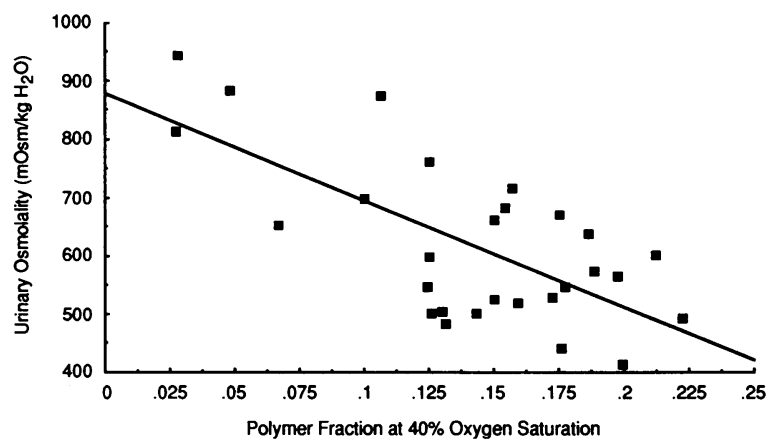

Figure 5. Relationship between mean urinary osmolality after intranasal dDAVP and mean percent polymer at 0.4 oxygen saturation in HbAS patients with four, three, and two $\alpha$-globin genes. $y=-1,835 x$ $+880 ; P<0.05$. 
the maximal urinary concentrating ability are frequently present in HbAS individuals $(1,32)$. Whereas these events rarely are clinically serious, their underlying mechanisms may provide insight into the pathogenesis of the vaso-occlusive complications of sickle cell disease.

Experimental measurements using ${ }^{13} \mathrm{C}$ NMR to quantitate intracellular polymer in HbAS cells showed a maximal polymer fraction of $\sim 0.35$ and a critical oxygen saturation for polymerization of 0.6 . These values can be calculated based upon the red cell indices and the percentage of $\mathrm{HbS}$ and $\mathrm{HbA}$, in HbAS cells with different $\alpha$-globin genotypes, under various conditions of oxygen saturation and $\operatorname{MCHC}(9,25)$. The solute concentration of the interstitium of the renal medulla may be as high as 1,200 mosmol (36), an osmolality that may dramatically increase MCHC. The MCHC has a strong effect on the extent of polymerization due to the crowding (or nonideal behavior) of hemoglobin molecules at physiologic concentrations (reflected in the exponential power dependence of the hemoglobin activity coefficient on hemoglobin concentration) (9). The combined effect of low oxygen saturation, that may reach 0.1 to 0.2 at the papillary tip (34), and increased MCHC would significantly increase the polymerization potential of the HbAS erythrocyte above those calculated for an oxygen saturation of 0.4 . For example, decreasing the oxygen saturation from 0.5 to 0.2 increases the polymer fraction by 0.15 at normal MCHC. Increasing $\mathrm{MCHC}$ by as little as $10 \%$ would further increase polymer fraction by another 0.10 at each of these oxygen saturation values. The correlation of polymer formation with renal concentrating defects would be little changed by these absolute changes in polymer formation as the ratio remains fairly constant. It is likely that when HbAS erythrocytes are exposed to this harsh physiologic environment, sickle hemoglobin polymer formation would be sufficient to alter the rheologic properties of the cell, perturb the medullary microvasculature, and lead to the measured inability to excrete a concentrated urine and hematuria.

If the extent of polymerization at any given oxygen saturation depends upon the percentage $\mathrm{HbS}$ within the erythrocyte, it could be expected that individuals with $\mathrm{HbAS}$ whose erythrocytes contain the highest $\mathrm{HbS}$ concentrations would have the greatest morbidity. $\alpha$-Thalassemia causes distinct hematological alterations when it is present with $\operatorname{HbAS}(17,18)$. Both the numbers and type of $\alpha$-gene deletion may influence these changes (37-40). As the $\alpha$-globin deficit increases, the level of $\mathrm{HbS}$ falls, because the $\beta^{3}$-chain competes less effectively than $\beta^{A}$-chain for the available $\alpha$-chain $(22,23)$. In our patients, at equivalent total hemoglobin concentrations, the percentage $\mathrm{HbS}$ varied trimodally, with means at $41.8,36.8$, and $29.2 \%$, in individuals with four, three, and two $\alpha$-globin genes, respectively, confirming earlier reports (13-15). Consequently, subjects with HbAS- $\alpha$-thalassemia would seem to be ideal individuals in whom to examine the effect of $\mathrm{HbS}$ concentration on the renal abnormalities of HbAS. The absence of deformed, dehydrated, and dense cells in the circulation, a characteristic of $\operatorname{HbSS}(39,41)$, might also afford the opportunity to differentiate the pathophysiologic effects of sickle polymer from those of the secondarily damaged red cell membrane of HbSS (42).

In earlier work, we found no relationship between percentage $\mathrm{HbS}$ and clinical events such as pulmonary embolus, myocardial infarction, stroke, and thrombophlebitis in men with $\mathrm{HbAS}$, separated into four groups on the basis of $\mathrm{HbS}$ level (43). In this study, hematuria was present in only three individ- uals with a $\mathrm{HbS}$ level of $<35 \%$, whereas it was found in nine patients with $\mathrm{HbS}>35 \%$, however, this result was not statistically significant. In a preliminary report, Reeves and associates (44) found that individuals with $\mathrm{HbAS}$ and a $\mathrm{HbS}$ concentration of $>38 \%$ did not concentrate their urine as well as subjects with a $\mathrm{HbS}$ level of $<38 \%$, after $6 \mathrm{~h}$ of water deprivation. These studies have suggested that $\alpha$-thalassemia may reduce the incidence of hematuria in HbAS. The current study extends the observations on urinary concentrating ability to include the range of $\mathrm{HbS}$ concentrations seen in $\mathrm{HbAS}$, calculates $\mathrm{HbS}$ polymer tendency, and examines maximal urinary concentrating ability. Our results show that the percentage $\mathrm{HbS}$ in $\mathrm{HbAS}$ erythrocytes directly determines the severity of the renal concentrating deficit in response to dDAVP. Furthermore, the observation that the calculated $\mathrm{HbS}$ polymer at oxygen saturations representative of those present in the renal medulla is also linearly correlated with the magnitude of the urinary concentrating defect in these individuals, is consistent with the hypothesis that the reduction in oxygen saturation in the medulla is an important factor in the induction of the renal lesion of this condition.

Despite these observations, a number of additional questions remain. First, it is uncertain whether the abnormalities causing the urinary concentrating defect in HbAS are due to structural damage to the renal medulla (4) or due to changes in blood flow per se. Second, several other functions of the distal nephron have been found to be abnormal in HbSS (45). Whether these are abnormal in $\mathrm{HbAS}$, where the level of $\mathrm{HbS}$ is considerably lower, requires further study. In this regard, Oster and associates have suggested that renal acidification is normal in HbAS (46), whereas Ho Ping Kong and Alleyne have reported lower urinary excretion rates of both ammonium and hydrogen ion in individuals with sickle trait (47).

In summary, the current study shows that the renal concentrating defect in HbAS is heterogeneous in severity and is directly related to the percentage of $\mathrm{HbS}$ and sickle polymer, at oxygen saturations representative of those present in the renal medulla. The intracellular HbS concentration was directly dependent on the $\alpha$-globin genotype. As in the clinically severe sickle hemoglobinopathies, intracellular HbS polymer influences the pathophysiology of HbAS.

\section{Acknowledgments}

We thank Alice Walker and Audrey Harrell for their technical assistance and Griffin P. Rodgers, M.D., for his helpful comments.

Supported in part by Research Funds of the Department of Veterans Affairs.

\section{References}

1. Serjeant, G. R. 1985. Sickle Cell Disease. Oxford University Press, Oxford $34 \mathrm{~N}$.

2. Harkness, D. R. 1989. Sickle cell trait revisited. Am. J. Med. 87:3-30N-3-

3. Perillie, P. E., and F. H. Epstein. 1963. Sickling phenomenon produced by hypertonic solutions: a possible explanation for the hyposthenuria of sicklemia. $J$. Clin. Invest. 42:570-580.

4. Statius van Eps, L. W., C. Pinedo-Veels, G. H. deVries, and J. deKoning. 1970. Nature of the concentrating defect in sickle cell nephropathy: microradioangiographic studies. Lancet. i:450-452.

5. Noguchi, C. T., and A. N. Schechter. 1981. The intracellular polymerization of sickle hemoglobin and its relevance to sickle cell disease. Blood. 58:10571068. 
6. Eaton, W. A., and J. Hofrichter. 1987. Hemoglobin S gelation and sickle cell disease. Blood. 70:1245-1266.

7. Schechter, A. N., C. T. Noguchi, and G. P. Rodgers. 1987. Sickle cell disease. In The Molecular Basis of Blood Diseases. G. Stammatoyannopoulos, A. W. Nienhuis, P. Leder, and P. W. Majerus, editors. W. B. Saunders Co. Philadelphia, PA. 179-218.

8. Noguchi, C. T., D. A. Torchia, and A. N. Schechter. 1981. Polymerization of sickle hemoglobin in sickle trait erythrocytes and lysates. J. Biol. Chem. 256:4168-4171

9. Noguchi, C. T. 1984. Polymerization in erythrocytes containing $\mathrm{S}$ and non-S hemoglobins. Biophys. J. 45:1153-1158.

10. Green, M. A., C. T. Noguchi, A. J. Keidan, S. S. Marwah, and J. Stuart. 1988. Polymerization of sickle hemoglobin at arterial oxygen saturation impairs erythrocyte deformability. J. Clin. Invest. 81:1669-1674.

11. Keiden, A. J., M. C. Sowter, C. S. Johnson, C. T. Noguchi, A. J. Girling, S. M. E. Stevens, and J. Stuart. 1989. Effect of polymerization tendency on haematological, rheological and clinical parameters in sickle cell anaemia. Br. J. Haematol: 71:551-557.

12. Bookchin, R. M., T. Balazs, and L. C. Landau. 1976. Determinations of red cell sickling. Effects of varying $\mathrm{pH}$ and of increasing intracellular hemoglobin concentration by osmotic shrinkage. J. Lab. Clin. Med. 87:597-616.

13. Nance, W. E., and J. Grove. 1972. Genetic determination of phenotypic variation in sickle cell trait. Science (Wash. DC). 177:716-718.

14. Weatherall, D. J., J. B. Clegg, J. Blankson, and J. R. McNeil. 1969. A new sickling disorder resulting from interaction of the genes for haemoglobin $\mathrm{S}$ and $\alpha$-thalassaemia. Br. J. Haematol. 17:517-526.

15. Huisman, T. H. J. 1977. Trimodality in the percentage of $\beta$ chain variants in heterozygotes: the effects of the number of active $\mathrm{Hb} \alpha$ structural loci. Hemoglo bin. 1:349-382.

16. Steinberg, M. H., J. G. Adams, and B. J. Dreiling. 1975. Alpha thalassemia in adults with sickle-cell trait. Br. J. Haematol. 30:31-37.

17. Embury, S. H., and A. M. Dozy. 1981 . The $\alpha$-globin genotype as a determinant of hematologic parameters in sickle cell trait. In The Molecular Basis of Mutant Hemoglobin Dysfunction. P. H. Sigler, editor. North-Holland Publishing Co., Amsterdam. 63-68.

18. Steinberg, M. H., and S. H. Embury. 1986. $\alpha$-Thalassemia in blacks: genetic and clinical aspects and interactions with the sickle hemoglobin gene. Blood. 68:985-990.

19. Dozy, A. M., Y. W. Kan, S. H. Embury, W. C. Mentzer, W. C. Wong, B Lubin, J. R. Davis, Jr., and H. N. Koenig. 1979. $\alpha$-Globin gene organization in blacks precludes the severe form of $\alpha$-thalassaemia. Nature (Lond.). 280:605-607.

20. Higgs, D. R., J. M. Old, J. B. Clegg, L. Pressley, D. M. Hunt, D. J. Weatherall, and G. R. Serjeant. 1979. Negro $\alpha$-thalassaemia is caused by deletion of a single $\alpha$-globin gene. Lancet. ii:272-276.

21. Liebhaber S. A., M. B. Coleman, J. G. Adams III, F. E. Cash, and M. H. Steinberg. 1987. Molecular basis for non-deletion $\alpha$-thalassemia in American blacks $\alpha^{116 G A G \rightarrow U A G}$. J. Clin. Invest. 80:154-159.

22. Bunn, H. F., and M. J. McDonald. 1983. Electrostatic interactions in the assembly of haemoglobin. Nature (Lond.). 306:498-500.

23. Bunn, H. F. 1987. Subunit assembly of hemoglobin: an important determinant of hematologic phenotype. Blood. 69:1-6.

24. Steinberg, M. H., M. B. Coleman, J. G. Adams III, R. C. Hartman, H Saba, and N. P. Anagnou. 1986. A new gene deletion in the $\alpha$-like globin gene cluster as the molecular basis for the rare $\alpha$-thalassemia-1 $(--/ \alpha \alpha)$ in Blacks: $\mathrm{Hb}$ $\mathrm{H}$ disease in sickle cell trait. Blood. 67:469-473.

25. Bunn, H. F., C. T. Noguchi, H. J. Hofrichter, G. P. Schechter, A. N Schechter, and W. A. Eaton. 1982. Molecular and cellular pathogenesis of hemoglobin SC disease. Proc. Natl. Acad. Sci. USA. 79:7527-7531.

26. Brugnara, C., H. F. Bunn, and D. C. Tosteson. 1986. Regulation of eryth- rocyte cation and water content in sickle cell anemia. Science (Wash. DC). 232:388-390.

27. Blin, N., and D. W. Stafford. 1976. A general method for isolation of high molecular weight DNA from eukaryotes. Nucleic Acids Res. 3:2303-2308.

28. Southern, E. M. 1975. Detection of specific sequences among DNA fragments separated by gel electrophoresis. J. Mol. Biol. 98:503-517.

29. Wilson, J. B., M. E. Headlee, and T. H. J. Huisman. 1983. A new high performance liquid chromatographic procedure for the separation and quantitation of various hemoglobins in adults and newborn babies. J. Lab. Clin. Med. 10:174-186.

30. Noguchi, C. T., D. A. Torchia, and A. N. Schechter. 1980. Determination of deoxyhemoglobin S polymer in sickle erythrocytes upon deoxygenation. Proc Natl. Acad. Sci. USA. 77:5487-5491.

31. Noguchi, C. T., D. A. Torchia, and A. N. Schechter. 1983. Intracellular polymerization of sickle hemoglobin: effects of cell heterogeneity. J. Clin. Invest. 72:846-852.

32. Bunn, H. F., and B. G. Forget. 1986. Hemoglobin: Molecular, Genetic and Clinical Aspects. W. B. Saunders Co., Philadelphia.

33. Wallenstein, S., C. L. Zucker, and J. L. Fleiss. 1980. Some statistical methods useful in circulation research. Circ. Res. 47:1-9.

34. Brezis, M., S. Rosen, P. Silva, and F. H. Epstein. 1984. Renal ischemia: a new perspective. Kidney Int. 26:375-383.

35. Heller, P., W. R. Best, R. B. Nelson, and J. Becktel. 1979. Clinical implications of sickle-cell trait and glucose-6-phosphate dehydrogenase deficiency in hospitalized black male patients. N. Engl. J. Med. 300:1001-1005.

36. Jamison, R. L., and R. H. Maffey. 1976. The urinary concentrating mechanism. N. Engl. J. Med. 295:1059-1067.

37. Fodde, R., M. Losekoot, M. H. van den Broek, M. Olgenburg, N. Rashida, A. Schreuder, J. T. Wijnin, P. C. Giordano, N. V. Nayudu, and P. M. Khan. 1988. Prevalence and molecular heterogeneity of alfa + thalassemia in two tribal populations from Andhra Pradesh, India. Human Genet. 80:157-160.

38. Embury, S. H., J. A. Miller, A. M. Dozy, Y. W. Kan, V. Chan, and D. Todd. 1980. Two different molecular organizations account for the single $\alpha$-globin gene of the $\alpha$-thalassemia-2 genotype. J. Clin. Invest. 66:1319-1325.

39. Bowden, D. K., A. V. S. Hill, D. R. Higgs, S. J. Oppenheimer, D. J. Weatherall, and J. B. Clegg. 1987. Different hematologic phenotypes are associated with leftward (- $-\alpha .2)$ and rightward $(-\alpha 3.7) \alpha$-thalassemia deletions. $J$. Clin. Invest. 79:39-43.

40. Embury, S. H. M. R. Clark, G. Monroy, N. Mohandas, and R. Hoesch. 1984. Concurrent sickle-cell anemia and $\alpha$-thalassemia: effect on pathological properties of sickle erythrocytes. J. Clin. Invest. 73:116-123.

41. Fabry, M. E., J. G. Mears, P. Patel, K. Schaefer-Rego, L. D. Charmichel, G. Martinez, and R. L. Nagel. 1984. Dense cells in sickle cell anemia: the effects of gene interaction. Blood. 64:1042-1046.

42. Hebbel, R. P. 1991. Beyond hemoglobin polymerization: the red blood cell membrane and sickle disease pathophysiology. Blood. 77:214-237.

43. Kennedy, A. P., D. A. Walsh, R. Nicholson, J. G. Adams, and M. H Steinberg. 1986. Influence of $\mathrm{HbS}$ levels upon the hematological and clinical characteristics of sickle cell trait. Am. J. Hematol. 22:51-54.

44. Reeves, J. D., B. H. Lubin, and S. H. Embury. 1984. Renal complications of sickle cell trait are related to the percent Hb S. Blood. 64(Suppl. 1):52. (Abstr)

45. Defronzo, R. A., P. A. Taufield, H. Black, P. McPhedran, and C. R. Cooke. 1979. Impaired renal tubular potassium secretion in sickle cell disease. Ann. Int. Med. 90:310-316.

46. Oster, J. R., S. M. Lee, L. E. Lespier, E. L. Pellegrini, and C. A. Vaamonde 1976. Renal acidification in sickle cell trait. Arch. Int. Med. 136:30-35.

47. Ho Ping Kong, H., and G. A. O. Alleyne. 1971. Studies on acid excretion in adults with sickle cell anemia. Clin. Sci. 41:505-581. 